\title{
The Transition Ratio of Nosema spp. Spores From Colonies to Honey Versus Honey to Colonies
}

\author{
Ceren Sarıbıyık ${ }^{1}$ \& Aslı Özkırım ${ }^{1,2}$ \\ ${ }^{1}$ Department of Biology, Hacettepe University, Ankara, Turkey \\ ${ }^{2}$ Bee and Bee Products Application and Research Center, Hacettepe University, Ankara, Turkey \\ Correspondence: Aslı Özkırım, Department of Biology, Hacettepe University, Beytepe-Ankara, 06800, Turkey. \\ Tel: 90-312-297-8043. E-mail: ozkirim@hacettepe.edu.tr
}

Received: September 16, 2018

Accepted: October 24, 2018

Online Published: December 15, 2018

doi:10.5539/jas.v11n1p72

URL: https://doi.org/10.5539/jas.v11n1p72

\begin{abstract}
Honey bees (Apis mellifera L.) are insects that have an important role in plant pollination as well as production of benefical products such as honey, propolis, pollen, royal jelly, bee venom and beeswax. There is a growing interest in bee diseases and loss, which is a major threat to the economy and human health. Nosemosis is an adult honey bee disease which effects its digestive system mostly. The cause for the disease is Nosema apis or Nosema ceranae but the two can be seen together, too. This article aims to explore the transmission of Nosemosis and its effect on honey. For this purpose, a field study was conducted in Muğla province, where 51 pieces were collected from bee yards as spring samples and 51 pieces from bee yards as autumn samples during these two seasons, and 51 honey samples from bee yards were examined during the honey harvest. The results revealed that Nosema spp. which was obtained from honey bee samples collected in spring was more effective on honey samples. Nosema spp. was found to have a linear relation with the infection in the hive. It was determined that the percentage of Nosema spores seen in adults was $1.63 \%$. This result contributed to the literature by providing this ratio used in estimating the level of infection in the colonies by means of honey sampling. Furthermore this is the first study where the contamination risk of honey from the infected colonies is calculated. Hopefully, this study can provide background for further research on the protection of bee colonies and risk assessment against Nosema spp. disease.
\end{abstract}

Keywords: Apis mellifera, Nosema apis, Nosema ceranae, honey, contamination, honey bee

\section{Introduction}

Honeybees have a crucial role to carry $75 \%$ of pollination, so honeybee colony losses is a great threat to the agricultural production globally. Of all the factors that threaten bees, Nosemosis is reported to be the most prevalent factor for colony losses all over the world (Huang et al., 2013; Botias et al., 2013). There is a growing interest in the newly detected microsporidian gut parasite Nosema ceranae because an unusually high honey bee colony mortality coincided with its apparent host-switch from Asian honey bees (Apis cerana) to honey bees (Fries, 2010), as well as its subsequent widespread dispersal (Williams et al., 2008). N. ceranae can cause tissue damage (Higes et al., 2008; Dussauabat et al., 2013), nutritional stress (Mayack \& Naug, 2009; Alaux et al., 2010) and suppression of host immunity (Chaimanee et al., 2012). In Spain, N. ceranae is typically associated with reduced colony survivorship (Higes et al., 2008), whereas in other parts of Europe (Genersch et al., 2010) and in North America (Guzman et al., 2010; Villa et al., 2013), its virulence is debated. Possible explanations for this variation include parasite or host genetics (Medici et al., 2012), climate (Chen et al., 2012), nutrition (Alaux et al., 2010), or interactions with other stressors such as environmental contaminants or other parasites (Pettis et al., 2013). That is why disappearing of honeybees must be investigated and in cases like Nosemosis infections, risk assessment should be practiced.

Nosema spp. is the pathogen of Nosemosis, a parasitic disease, which effects the adult bees at a global scale. It is a genus of fungi which belongs to Microsporidia (Fries, 1993, 2010). There are two species Nosema apis and Nosema ceranae. Colonies infected by Nosemosis show the following symptoms: reluctance to fly, abdominal swelling, dyspepsia, and leaving the hive. Recently, this is the most important reason of colony losses reported all over the world. (Botias et al., 2013; Fries, 2010; Fenoy et al., 2009; Chen et al., 2008; Martin-Hernández et al., 2007; Hornitzky, 2005; Webster et al., 2004). 
This kind of colony loss can be classified either as colony depopulation or colony collapse. In such kind of colonies, what remains is only the honey and the combs. It was reported earlier that Nosema spp. spores permeate to honey and stays alive (Giersch et al., 2009; Gisder et al., 2010; Peukpiboon et al., 2017). In such cases beekeepers use these combs in other hives or feed them with the contaminated honey, which both increase the faster spread of Nosema spores to other colonies.

The aim of this study is to determine the transition rate of Nosema spp. spores to honey. Thus it will be possible to calculate the infection level of the collapsed colony by formulating the counts of spores which are harvested from the infected hives, and the level of risk it poses to the healthy colonies. Using the same formula in an infected colony, the rate of spores spread to honey can also be defined.

\section{Method}

\subsection{The Field Trial and Sample Collection}

In this study, samples which were collected from the apiaries in Muğla province were studied by means of Nosema spp. Muğla province is located in South-east Turkiye (Figure 1). Among all other provinces, Muğla was selected for sample collection mainly because the Pine honey is produced in Muğla region, so Nosema spp. spores found in honey are not outsource related because of pollens carried to hive but, it is because of colony origin. In pine honey production, bees only visit pine trees and they only collect honeydew. Field trials were organized during spring and autumn in order to collect samples. There were 102 different apiaries, and 30 adult bees were collected from each. Totally 3060 adult bees were collected and sent to Hacettepe University Bee Health Laboratory and kept in fridges $4{ }^{\circ} \mathrm{C}$ during the time of research.

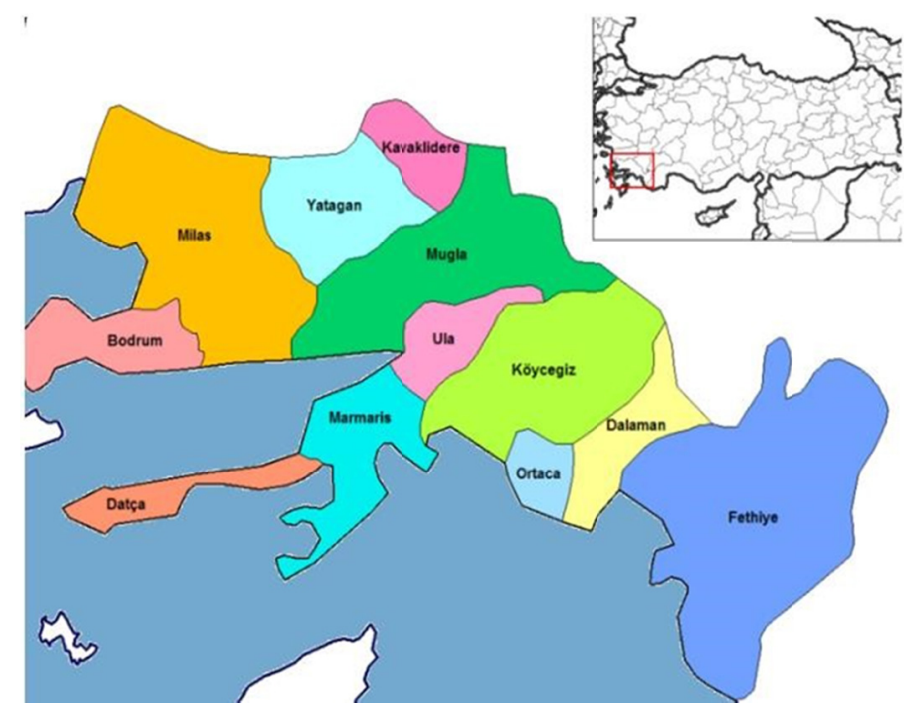

Figure 1. The map of Muğla Province

Source: http://muglave.blogspot.com.tr/2014/01/muglave-ilceleri.html

\subsection{The Nosema spp. Analyses of Samples}

\subsubsection{The Analyses of Adult Bees}

The samples were carefully dissected and mixed with water. The solution contained 5-50 particles per square. The sample was mixed properly to ensure uniform/ homogenous suspension before introducing the suspension to the periphery of one of the v-shaped wells with pipette. The area under the cover slip fills by capillary action. Then, haemocytometer was placed under microscope, adjusted to appropriate magnification. The spores were counted in the appropriate squares depending on the size of the particles to be counted, making sure that different areas of the chamber are counted. At least 300 particles were counted in order to minimise errors. The number of particles were calculated per $\mathrm{ml}$ of the original sample from the known volume of the counting chamber. In order to obtain the total number of particles in the sample, the number of spores were multiplied the concentration obtained by the initial sample volume (OIE Manual, 2008). 


\subsubsection{The Analyses of Honey}

In order to determine the Nosema in the honey, $1 \mathrm{~g}$ of honey was put into two flacons. $9 \mathrm{ml}$ sterilized saline solution (SSS- $0.9 \%$ ) was added and vortexed in order to homogenize it. The solution gathered was centrifuged for 10 minutes in $3000 \mathrm{rpm}$. After centrifugation, the supernatant was poured out and vortexed again after adding $1 \mathrm{ml}$ of SSS to pellet. Out of this ready mixture $0.1 \mathrm{ml}$ was examined in Improved Neubauer slide by applying abdominal Nosema counting method and the Nosema spp. spores were expressed. In other words, this study adapts Nosema spore counting method for adult bees to spore counting from honey samples.

\subsection{Statistical Analyses}

The Nosema spp. spore counts both from honey samples and adult bee samples were studied and the data obtained from the statistical analyses were presented as $\mathrm{R}$ programming output. According to this; for the Nosema spp. inclusion of both adult bee samples and honey samples, Regression Analysis (The R Project for Statistical Computing https://www.r-project.org) was made and in order to prove it "one way variance analysis" (ANOVA) was applied. The linear correlation between Nosema spp. counts of hive and honey was observed by Pearson Correlation coefficient test. The Nosema spp. spore volumes for Spring and Autumn samples of adult bees which were abdominally examined were expressed by paired t-test to seasons.

\section{Results}

As a result of microscopic investigations in adult honey bee samples both for Spring and Autumn, N.ceranae spores were observed in 20 samples, $N$. apis spores were observed in 13 samples, and both $N$. apis and N. ceranae were observed together in 69 samples (Figure 2).

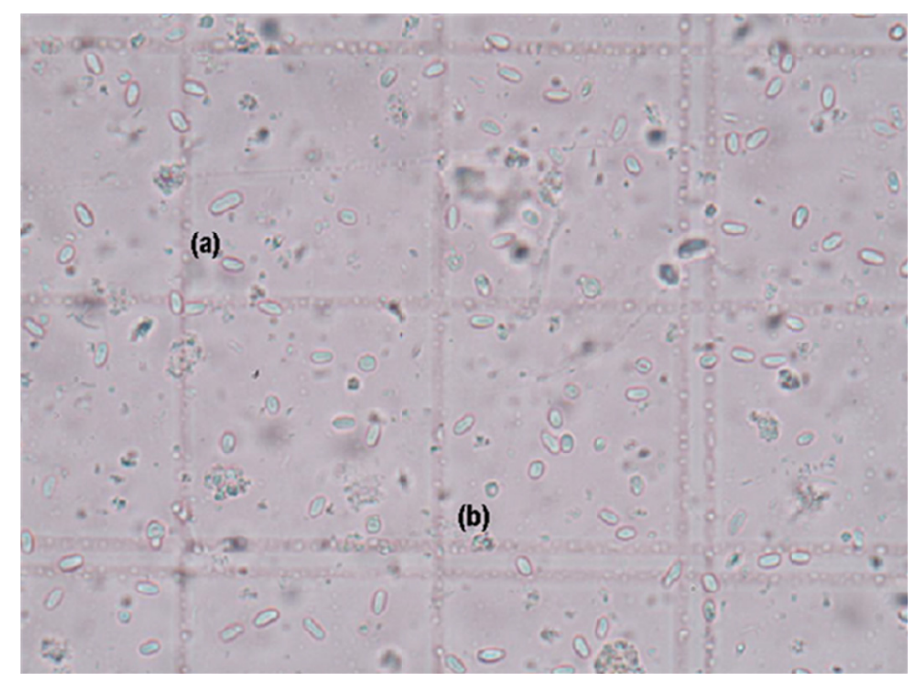

Figure 2. The Nosema spp. spores under the light microscope (×40) (a) N. apis, (b) N. ceranae (Photo by Sarıbıyık 2018)

Nosema spp. spore counts out of samples of adult honey bees which are collected during Spring and Autumn are summarized in Table 1. 
Table 1. The number of Nosema spp. spores/bee in adult bee samples collected during spring and autumn seasons

\begin{tabular}{|c|c|c|c|c|c|}
\hline \multirow{2}{*}{ Sample No } & Spring & Autumn & \multirow{2}{*}{ Sample No } & Spring & Autumn \\
\hline & \multicolumn{2}{|c|}{--- The number of Nosema spp. spores $\left(\times 10^{6}\right)$--- } & & \multicolumn{2}{|c|}{--- The number of Nosema spp. spores $\left(\times 10^{6}\right)$--- } \\
\hline 1 & 0.4 & 0.8 & 27 & 0.5 & 0.6 \\
\hline 2 & 1.2 & 0.8 & 28 & 2.2 & 1.1 \\
\hline 3 & 1.4 & 0.9 & 29 & 2.9 & 2.4 \\
\hline 4 & 2 & 1 & 30 & 3.3 & 8.2 \\
\hline 5 & 2.1 & 1.3 & 31 & 5.9 & 9.5 \\
\hline 6 & 2.3 & 1.3 & 32 & 6.5 & 12.3 \\
\hline 7 & 2.6 & 1.8 & 33 & 12.5 & 13.8 \\
\hline 8 & 2.7 & 3.6 & 34 & 0.9 & 0.5 \\
\hline 9 & 4 & 4.1 & 35 & 0.8 & 0.8 \\
\hline 10 & 6.7 & 5.0 & 36 & 1.1 & 0.9 \\
\hline 11 & 15.3 & 7.6 & 37 & 2 & 1.8 \\
\hline 12 & 0.6 & 0.3 & 38 & 2.2 & 2.2 \\
\hline 13 & 2.6 & 0.6 & 39 & 0.8 & 0.5 \\
\hline 14 & 4.5 & 5.8 & 40 & 0.8 & 0.5 \\
\hline 15 & 7.8 & 5.9 & 41 & 2 & 0.8 \\
\hline 16 & 15.8 & 6.9 & 42 & 4.8 & 2.2 \\
\hline 17 & 19.1 & 16.3 & 43 & 1.1 & 0.8 \\
\hline 18 & 25 & 19.3 & 44 & 1.3 & 1.3 \\
\hline 19 & 1.1 & 0.6 & 45 & 2.9 & 2.8 \\
\hline 20 & 1.8 & 1.1 & 46 & 8.5 & 5.4 \\
\hline 21 & 3.4 & 1.4 & 47 & 0.8 & 0.4 \\
\hline 22 & 4.6 & 2.6 & 48 & 2.7 & 1.4 \\
\hline 23 & 4.8 & 8.2 & 49 & 9.1 & 5.1 \\
\hline 24 & 5.7 & 10.7 & 50 & 4.6 & 2.2 \\
\hline 25 & 9.5 & 4.9 & 51 & 9.8 & 4.4 \\
\hline 26 & 12.6 & 8.3 & & & \\
\hline \multirow{2}{*}{\multicolumn{2}{|c|}{$\begin{array}{l}\text { Mean number of } \\
\text { Nosema spp. }\left(\times 10^{6}\right)\end{array}$}} & Spring & & 4.9 & \\
\hline & & Autumn & & 4 & \\
\hline
\end{tabular}

Nosema spp. spores counts obtained from honey samples (Figure 3). The comparison of same colony's Nosema spp. Counts of spring and autumn samples were summarized (Table 2).

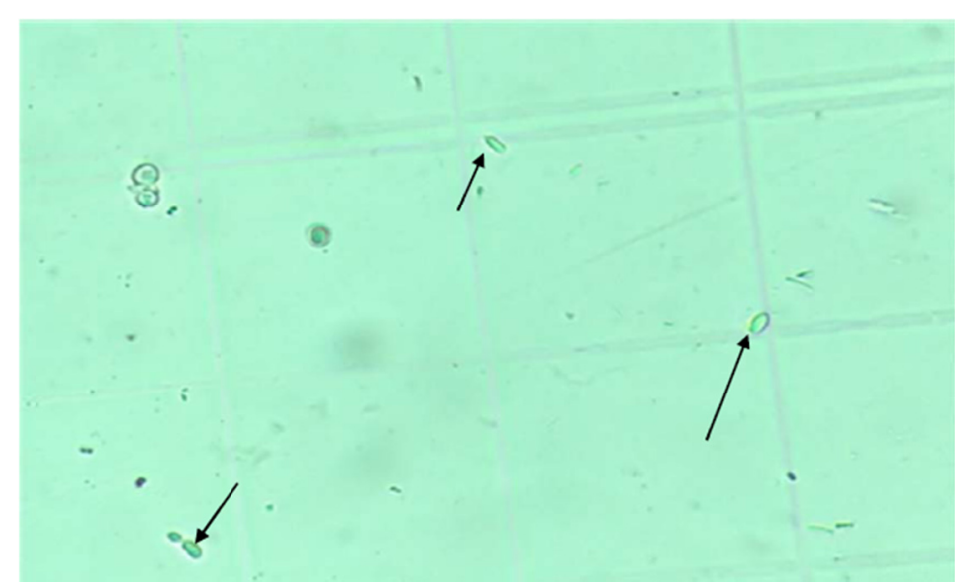

Figure 3. The Nosema spp. spores in honey samples under the light microscope $(\times 40)$ (Photo by Sarıbiyık 2018). 
Table 2. The comperative results of Nosema spp. analyses in colonies spring and autumn seasons and honey samples

\begin{tabular}{|c|c|c|c|c|c|c|c|}
\hline \multirow{2}{*}{ Sample No } & Spring & Autumn & Honey & \multirow{2}{*}{ Sample No } & Spring & Autumn & Honey \\
\hline & \multicolumn{3}{|c|}{--- The number of Nosema spp. spores $\left(\times 10^{6}\right)$--- } & & \multicolumn{3}{|c|}{--- The number of Nosema spp. spores $\left(\times 10^{6}\right)$--- } \\
\hline 1 & 0.4 & 0.8 & 0.0 & 27 & 0.5 & 0.6 & 0 \\
\hline 2 & 1.2 & 0.8 & 0.0 & 28 & 2.2 & 1.1 & 0.03 \\
\hline 3 & 1,4 & 0.9 & 0.03 & 29 & 2.9 & 2.4 & 0.05 \\
\hline 4 & 2 & 1 & 0.03 & 30 & 3.3 & 8.2 & 0.08 \\
\hline 5 & 2.1 & 1.3 & 0.03 & 31 & 5.9 & 9.5 & 0.11 \\
\hline 6 & 2.3 & 1.3 & 0.05 & 32 & 6.5 & 12.3 & 0.11 \\
\hline 7 & 2.6 & 1.8 & 0.05 & 33 & 12.5 & 13.8 & 0.22 \\
\hline 8 & 2.7 & 3.6 & 0.08 & 34 & 0.9 & 0.5 & 0 \\
\hline 9 & 4 & 4.1 & 0.08 & 35 & 0.8 & 0.8 & 0 \\
\hline 10 & 6.7 & 5.0 & 0.08 & 36 & 1.1 & 0.9 & 0 \\
\hline 11 & 15.3 & 7.6 & 0.17 & 37 & 2 & 1.8 & 0.05 \\
\hline 12 & 0.6 & 0.3 & 0 & 38 & 2.2 & 2.2 & 0.05 \\
\hline 13 & 2.6 & 0.6 & 0.03 & 39 & 0.8 & 0.5 & 0 \\
\hline 14 & 4.5 & 5.8 & 0.08 & 40 & 0.8 & 0.5 & 0 \\
\hline 15 & 7.8 & 5.9 & 0.08 & 41 & 2 & 0.8 & 0.03 \\
\hline 16 & 15.8 & 6.9 & 0.17 & 42 & 4.8 & 2.2 & 0.08 \\
\hline 17 & 19.1 & 16.3 & 0.31 & 43 & 1.1 & 0.8 & 0 \\
\hline 18 & 25 & 19.3 & 0.38 & 44 & 1.3 & 1.3 & 0.03 \\
\hline 19 & 1.1 & 0.6 & 0 & 45 & 2.9 & 2.8 & 0.08 \\
\hline 20 & 1.8 & 1.1 & 0.03 & 46 & 8.5 & 5.4 & 0.11 \\
\hline 21 & 3.4 & 1.4 & 0.05 & 47 & 0.8 & 0.4 & 0 \\
\hline 22 & 4.6 & 2.6 & 0.08 & 48 & 2.7 & 1.4 & 0.05 \\
\hline 23 & 4.8 & 8.2 & 0.08 & 49 & 9.1 & 5.1 & 0.11 \\
\hline 24 & 5.7 & 10.7 & 0.11 & 50 & 4.6 & 2.2 & 0.08 \\
\hline 25 & 9.5 & 4.9 & 0.11 & 51 & 9.8 & 4.4 & 0.11 \\
\hline 26 & 12.6 & 8.3 & 0.14 & & & & \\
\hline
\end{tabular}

Nosema spp. counts out of adult bees and honey samples collected in spring and autumn were both investigated and the data obtained according to the statistical analysis were presented by R programming output. (According to the Regression Analysis R programming ouput in order to define the origin of Nosema spp.spores) Residual standard error: 0.01695 on 48 degrees of freedom Multiple R-squared: 0.9521, Adjusted R-squared: 0.9501 F-statistic: 476.9 on 2 and 48 DF, p-value: $<2.2 \mathrm{e}-16$

The multiple R-square value obtained was very close to 1 , meaning that Nosema spp. spores in the honey is mostly caused by Nosema spp. infection of the colony.

One sided variance analysis (ANOVA) was applied in order to prove the statistical significance of this analysis. The results of this anlaysis according to R programming output are: Df 1 Sum Sq 0.27319 Mean Sq 0.273190 F value $920.68<2.2 \mathrm{e}-16 \operatorname{Pr}(>\mathrm{F})$ Residuals 490.014540 .000297 Signif. codes: 0 '***' 0.001 '**' 0.01 '*' 0.05 '?' $0.1^{\prime}$ ' 1 The value of $\operatorname{Pr}>0.05$ the Nosema variable is significant. The linear relationship between Nosema spp. counts of hive and honey was observed by Pearson Correlation coefficient test; data: nosema.ss and nosema in honey $\mathrm{t}=30.343, \mathrm{df}=49$, $\mathrm{p}$-value $<2.2 \mathrm{e}-16$ alternative hypothesis: true correlation is not equal to 0.95 percent confidence interval: 0.95536840 .9853844 sample estimates: cor 0.9744065 .

According to this result, the correlation variant is bigger than 0 and equal to 1 ; the correlation between the honey samples and adult bee samples is significant. A graph of Nosema spores count, prepared with the average spring and autumn adult bee samples and honey samples can easily show the correlation (Figure 4). 


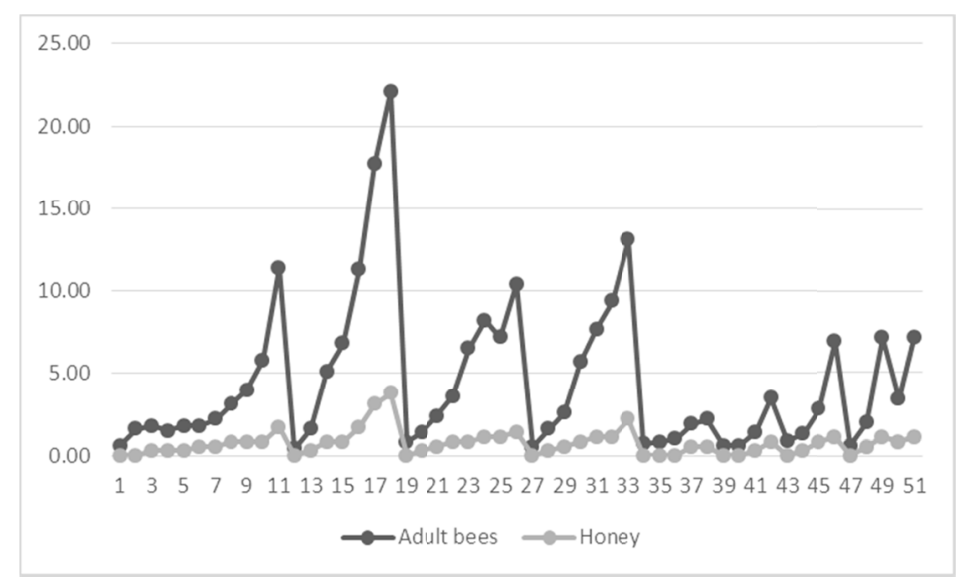

Figure 4. The parallel view of data of Nosema spp. spores in adult bees and honey (the data coming from honey is used by 10 fold in order to create the line on the graph)

The Nosema spp. spore volumes for Spring and Autumn samples of adult bees which were abdominally examined were expressed by Paired t-test related to seasons.According to the statistical studies the data is in line with the R programming outcome; Paired t-test data: Spring and Autumn $t=2.3576, \mathrm{df}=50, \mathrm{p}$-value $=0.02235$ alternative hypothesis: true difference in means is not equal to 095 percent confidence interval: 0.1352849 1.6921661 sample estimates: mean of the differences 0.9137255

As p-value $<0.05$ the difference between the seasons is significant. Nosema spp. spore volume results of abdominal inspection of the adult honey bee samples collected in autumn were compared with Honey samples. The data of statistical analysis according to Pearson Correlation Test $\mathrm{R}$ programming were; Pearson's product-moment correlation data: Autumn and Nosema in honey $\mathrm{t}=15.82, \mathrm{df}=49$, $\mathrm{p}$-value $<2.2 \mathrm{e}-16$ alternative hypothesis: true correlation is not equal to 095 percent confidence interval: 0.85415860 .9505185 sample estimates: cor 0.9144807.

Nosema spp. spore counts results of abdominal dissection of the adult honey bee samples collected in Spring were compared with honey samples. The data of statistical analysis according to Pearson Correlation Test $\mathrm{R}$ programming were; Pearson's product-moment correlation data: Pearson's product-moment correlation data: Spring and nosema in honey $\mathrm{t}=22.763, \mathrm{df}=49$, $\mathrm{p}$-value $<2.2 \mathrm{e}-16$ alternative hypothesis: true correlation is not equal to 095 percent confidence interval: 0.92350060 .9746710 sample estimates: cor 0.9558252

The transition of Nosema spp. spores from colony to honey was found $1.63 \%$ (transfer ratio) based on the correlation data gathered from all statistical analysis. In this way, either the contamination risk of honey from the infected hive or vice versa the Nosema infection rate of a hive can be predicted from the honey samples. Below formulas are created to calculate the estimated spore counts.

$$
\text { Nosema spp. spore count of the colony (spores } / \text { bee })=\frac{100 \times \mathrm{NH}^{*}}{1.63}
$$

Where, *NH: Nosema spp. in Honey.

$$
\text { Nosema spp. spore count of Honey (spores } / \mathrm{gr})=\frac{1.63 \times \mathrm{NB}^{* *}}{1.63}
$$

Where, ${ }^{*}$ NB: Nosema spp. in Bee.

For example; in a honey sample contaminated with $0.08 \times 10^{6}$ spores this means that the infection level in a colony fed by this honey would be $100 \times 0.08 / 1.63=4.9 \times 10^{6}$ spores/bee, or the infection level in an infected colony is $6.1 \times 10^{6}$ spores/bee this means that infection level in honey is $1.63 \times 6.1 / 100=0.09 \times 10^{6}$ spores/gr.

When the samples of two seasons' correlations were compared with each other Spring correlation was found bigger. As a result it was found that Nosema spp. spores contaminates the honey more in Spring season.

\section{Discussion}

Nosemosis, also known as the "silent killer" by beekeepers due to its lack of a significant symptom, can be one of the most important reasons of colony losses in rainy and especially warm places (Fries, 1993; Malone et al., 2001; Williams et al., 2014; Gisder et al., 2010; Stevanovic et al., 2010). 
This study conducted in Muğla tries to answer the following questions; what is the effect of Nosema spore contamination of honey in production of Pine Honey and the infection rate of Nosema spp. spores to contamination rate? The main reason for selecting Muğla and Pine Honey was to ensure the contamination was only from adult bees and to minimize the effects of other sources of infection like water pollens etc. because during Pine Honey production season, there aren't any pollen sources. In the test performed to understand the correlation between Nosema spp. in adult bee samples and the Nosema spp. in honey Multiple R-squared value has been calculated close to 1 . This value is expected to be between 0 and 1 and when it is closer to 1 it proves that the nosema ssp in honey is hive sourced. After defining that the Nosema spp in the honey is sourced by colony infection, the second aim was to prove its statistical significance, thus "one-way ANOVA" was used in this study. According to ANOVA results, if $\operatorname{Pr}>0.05$, Nosema spp. variable in the hive is significant. The relationship between the Nosema spp. counts in the colony and the Nosema spp. counts in the honey were analyzed by Pearson correlation test and correlation value was defined. The value is a positive value $(0.9744065)$ which proves that there is a direct relation in counts of Nosema spp. between colony and honey. This has importance for further studies to calculate the infection rate in both sides. When the same case applied in flower honey at least the minimum rate of infection from the adult bees can be calculated and then additional other sources of infections can be considered (Peukpiboon et al., 2017).

As it is shown in Figure 4. as the counts of Nosema spp. levels increased the level in the honey also increases unless infection level is not over the threshold value (threshold value $=200.000$ spores/bee). Under this value Nosema spp. spores are not found in honey and this clears that Nosema spp. spores were found in 39 of 51 honey samples. This also coincides with the contamination from colony to honey ratio $1.63 \%$.

The samples collected were also studied by "paired t-test" statistically in order to define the differences according to seasons and was found p-value $<0.05$ significant. Statistically, seasons effect the contamination of Nosema spp. Main reason for this can be migratory beekeeping during spring season. In this season colony number increases and they are kept very close to each other, however during pine honey production period $75 \%$ of 7 million colonies migrate to Muğla.

When the transition rate of Nosema spp. from adult bees to honey is studied according to seasons (paired-t test p-value $<0.05)$ the correlation value is higher in Spring season. In other words, the Nosema spp. inflation in Spring increases the Nosema spp. spore counts more than it does in Autumn. This can be due to the fact that spring time is closer to honey production period and spores can be more viable. Viability of the spores can be less in Autumn samples which has passed a cold winter season. This result matches with other reports from different countries (Malone et al., 2001; Mayack \&d Naug 2009; Fenoy et al., 2009; Williams et al., 2014; Gisder et al., 2010; Stevanovic et al., 2010).

This is the first study that determines the transition of Nosema spp. spore to honey and its risk ratio. By finding the Nosema spp. spore counts in the colony, out of honey samples will be a corner stone for further studies. This study shows that the higher prevalence of Nosema spp. could be kept at a minimum level by means of using these formulas to calculate Nosema spp. transition cycles from colonies to honey and vice versa. And also, it can determine the migratory beekeeping routes, hive capacities of places etc. to prevent colonies from Nosema diseases.

\section{References}

Alaux, C., Ducloz, F., Crauser, D., \& Le Conte, Y. (2010). Diet effects on honeybee immunocompetence. Biology Letters, 6, 562-565. https://doi.org/10.1098/rsbl.2009.0986

Botias, C., Martín-Hernández, R., Barrios, L., Meana, A., \& Higes, M. (2013). Nosema spp. infection and its negative effects on honey bees (Apis mellifera iberiensis) at the colony level. Vet. Res., 44(25).

Chaimanee, V., Chantawannakul, P., Chen, Y. P., Evans, J. D., \& Pettis, J. S. (2012). Differential expression of immune genes of adult honey bee (Apis mellifera) after inoculated by Nosema ceranae. Journal of Insect Physiology, 58, 1090-1095. https://doi.org/10.1016/j.jinsphys.2012.04.016

Chen, Y. W., Evans, J. D., Smith, I. B., \& Pettis, J. S. (2008). Nosema ceranae is a longpresent and wide-spread microsporidian infection of the European honey bee (Apis mellifera) in the United States. J Invertebr Pathol, 97, 186-188. https://doi.org/10.1016/j.jip.2007.07.010

Chen, Y. W., Chung, W. P., Wang, C. H., Softer, L. F., \& Huang, W. F. (2012). Nosema ceranae infection intensity highly correlates with temperature. Journal of Invertebrate Pathology, 111, 264-267. https://doi.org/10.1016/j.jip.2012.08.014 
Dussaubat, C., Sagastume, S., Gomez-Moracho, T., Botias, C., \& Garcia-Palencia, P. (2013). Comparative study of Nosema ceranae (Microsporidia) isolates from two different geographic origins. Veterinary Microbiology, 162, 670-678. https://doi.org/10.1016/j.vetmic.2012.09.012

Fenoy, S., Rueda, C., Higes, M., Martín-Hernández, R., \& del Aguila, C. (2009). High-level resistance of Nosema ceranae, a parasite of the honeybee, to temperature and desiccation. Appl. Environ. Microbiol., 75, 6886-6889. https://doi.org/10.1128/AEM.01025-09

Fries, I. (2010). Nosema ceranae in European honey bees (Apis mellifera). J. Invertebr. Pathol., 103, 573-579. https://doi.org/10.1016/j.jip.2009.06.017

Fries, I. (1993). Nosema apis-A parasite in the honey bee colony. Bee World, 74, 5-19. https://doi.org/10.1080/ 0005772X.1993.11099149

Genersch, E., von der Ohe, W., Kaatz, H., Schroeder, A., \& Otten, C. (2010). The German bee monitoring project: a long term study to understand periodically high winter losses of honey bee colonies. Apidologie, 41, 33-352. https://doi.org/10.1051/apido/2010014

Giersch, T., Berg, T., Galea, F., \& Hornitzky, M. (2009). Nosema ceranae infects honey bees (Apis mellifera) and contaminates honey in Australia. Apidologie, 40, 117-123. https://doi.org/10.1051/apido/2008065

Gisder, S., Hedtke, K., Möckel, N., Frielitz, M. C., Linde, A., \& Genersch, E. (2010). Five-year cohort study of Nosema spp. in Germany: Does climate shape virulence and assertiveness of Nosema ceranae? Applied and Environmental Microbiology, 76, 3032-3038. https://doi.org/10.1128/AEM.03097-09

Guzman-Novoa, E., Eccles, L., Calvete, Y., McGowan, J., \& Kelly, P.G. (2010). Varroa destructor is the main culprit for the death and reduced populations of overwintered honey bee (Apis mellifera) colonies in Ontario, Canada. Apidologie, 41, 443-450. https://doi.org/10.1051/apido/2009076

Higes, M., Martin-Hernandez, R., Botias, C., Bailon, E. G., \& Gonzalez-Porto, A. V. (2008). How natural infection by Nosema ceranae causes honeybee colony collapse. Environmental Microbiology, 10, 2659-2669. https://doi.org/10.1111/j.1462-2920.2008.01687.x

Hornitzky, M. (2005). Nosema disease, Nosema disease literature review and survey of beekeepers (RIRDC Publication 05-005, 18).

Malone, H., Gatehouse, H. S., \& Tregidga, E. L. (2001). Effects of time, temperature, and honey on Nosema apis (Microsporidia: Nosematidae), a parasite of the honeybee, Apis mellifera (Hymenoptera: Apidae). Journal of Invertebrate Pathology, 77, 258-268. https://doi.org/10.1006/jipa.2001.5028

Martin-Hernández, R., Meana, A., Prieto, L., Martínez Salvador, A., GarridoBailón, E., \& Higes, M. (2007). Outcome of colonization of Apis mellifera by Nosema ceranae. Applied and Environmental Microbiology, 73, 6331-6338. https://doi.org/10.1128/AEM.00270-07

Mayack, C., \& Naug, D. (2009). Energetic stress in the honeybee Apis mellifera from Nosema ceranae infection. Journal of Invertebrate Pathology, 100, 185-188. https://doi.org/10.1016/j.jip.2008.12.001

Medici, S. K., Sarlo, E. G., Porrini, M. P., Braunstein, M., \& Eguaras, M. J. (2012). Genetic variation and widespread dispersal of Nosema ceranae in Apis mellifera apiaries from Argentina. Parasitology Research, 110, 859-864. https://doi.org/10.1007/s00436-011-2566-2

OIE. (2008). Nosemosis of Honey Bees, Manual of Standards for Diagnostic Tests and Vaccines: Bee Diseases. OIE, Paris, France.

Pettis, J. S., Lichtenberg, E. M., Andree, M., Stitzinger, J., \& Rose, R. (2013). Crop pollination exposes honey bees to pesticides which alters their susceptibility to the gut pathogen Nosema ceranae. Plos One, 8, e70182. https://doi.org/10.1371/journal.pone.0070182

Peukpiboon, T., Benbow, M. E., \& Suwannapong, G. (2017). Detection of Nosema spp. spore contamination in commercial Apis mellifera bee pollens of Thailand. Journal of Apicultural Research, 56(4), $376-386$. https://doi.org/10.1080/00218839.2017.1327936

Stevanovic, J., Stanimirovic, Z., Genersch, E., Kovacevic, S. R., Ljubenkovic, J., Radakovic, M., \& Aleksic, N. (2010). Dominance of Nosema ceranae in honey bees in the Balkan countries in the absence of symptoms of colony colopse disorder. Apidologie, 42, 49-58. https://doi.org/10.1051/apido/2010034 
Villa, J. D., Bourgeois, A. L., \& Danka, R. G. (2013). Negative evidence for effects of genetic origin of bees on Nosema ceranae, positive evidence for effects of Nosema ceranae on bees. Apidologie, 44, 511-518. https://doi.org/10.1007/s13592-013-0201-1

Webster, T. C., Pomper, K. W., Hunt, G., Thacker, E. M., \& Jones, S. C. (2004). Nosema apis infection in worker and queen Apis mellifera. Apidologie, 35, 49-54. https://doi.org/10.1051/apido:2003063

Williams, G. R., Sampson, M. A., Shutler. D., \& Rogers. R. E. L. (2008). Does fumagillin control the recently detected invasive parasite Nosema ceranae in western honey bees (Apis mellifera)? Journal of Invertebrate Pathology, 99, 342-344. https://doi.org/10.1016/j.jip.2008.04.005

Williams, G. R., Shutler, D., Burgher-MacLellan, K. L., \& Rogers, R. E. L. (2014). Infra-population and community dynamics of the parasites Nosema apis and Nosema ceranae, and consequences for honey bee (Apis mellifera) hosts. PLoS One, 9, e99465. https://doi.org/10.1371/journal.pone.0099465

\section{Copyrights}

Copyright for this article is retained by the author(s), with first publication rights granted to the journal.

This is an open-access article distributed under the terms and conditions of the Creative Commons Attribution license (http://creativecommons.org/licenses/by/4.0/). 